\title{
Provider preferences for delivery of HIV care coordination services: results from a discrete choice experiment
}

Rebecca Zimba, $\mathrm{MHS}^{1 \S}$, Chunki Fong, $\mathrm{MS}^{1}$, Madellena Conte, $\mathrm{MS}^{1}$, Abigail Baim-Lance, $\mathrm{PhD}^{1}$, McKaylee Robertson, $\mathrm{PhD}^{1}$, Jennifer Carmona, $\mathrm{MPH}^{2}$, Gina Gambone, $\mathrm{MPH}^{2}$, Denis Nash, $\mathrm{PhD}, \mathrm{MPH}^{1,3}$, Mary Irvine, DrPH, $\mathrm{MPH}^{2}$

1 Institute for Implementation Science in Population Health (ISPH), City University of New York (CUNY), New York, USA

2 Bureau of HIV, New York City Department of Health and Mental Hygiene, New York, USA

3 Department of Epidemiology and Biostatistics, Graduate School of Public Health and Health Policy, City University of New York (CUNY), New York, USA

${ }^{\S}$ Corresponding author: Rebecca Zimba

$55 \mathrm{~W} 125^{\text {th }}$ Street, $6^{\text {th }}$ Floor

New York, NY 10027, United States

Phone: 1-646-364-9618

Fax: 1-646-786-3894

rebecca.zimba@sph.cuny.edu

Keywords: discrete choice experiment; HIV; antiretroviral therapy; adherence; care coordination; New York City;

Word count:

Abstract $=259 / 350$

Manuscript $=3157 / 3500$ 


\section{Abstract}

\section{Introduction}

3 The PROMISE study was launched in 2018 to assess and document the implementation of

4 changes to an existing HIV Care Coordination Program (CCP) designed to address persistent

5 disparities in care and treatment engagement among persons with HIV in New York City. We

6 evaluated provider endorsement of features of the CCP to identify opportunities for

7 improvement.

\section{Methods}

We used a discrete choice experiment (DCE) to measure provider endorsement of four CCP

11 attributes, including: a) how CCP helps with medication adherence, b) how CCP helps with

12 primary care appointments, c) how CCP helps with issues other than primary care, and d) where

13 CCP visits take place (visit location). Each attribute had three to four levels. Our primary

14 outcomes were relative importance and part-worth utilities, measures of preference for the levels

15 of the four CCP program attributes.

\section{Results}

18 Visit location (28.6\%) had the highest relative importance, followed by how staff help with ART

19 adherence (24.3\%), how staff help with issues other than primary care $(24.2 \%)$, and how staff

20 help with primary care appointments (22.9\%). Within each of the above attributes, respectively,

21 the levels with the highest part-worth utilities were home visits 60 minutes from the program or

22 agency (19.9 utiles, 95\% CI 10.7-29.0), directly observed therapy (26.1 utiles, 95\% CI 19.1-

23 33.1), help with non-HIV specialty medical care (26.5 utiles, 95\% CI 21.5-31.6), and reminding 
medRxiv preprint doi: https://doi.org/10.1101/2021.10.21.21265350; this version posted October 25, 2021. The copyright holder for this preprint

(which was not certified by peer review) is the author/funder, who has granted medRxiv a license to display the preprint in perpetuity.

24 clients about and accompanying them to primary care appointments (20.8 utiles, 95\% CI 15.6-

25 26.0).

26

\section{Conclusions}

28 Ongoing CCP refinements should account for how best to support and evaluate the intensive

29 CCP components endorsed by providers in this study. 


\section{Introduction}

Antiretroviral therapy (ART) adherence improves clinical outcomes among persons with HIV $(\mathrm{PWH})$ and reduces onward transmission of the virus [1-4]. However, in the United States, the diagnosed with HIV in 2017 and alive at the end of 2018 had achieved viral suppression ( $\leq 200$ copies/mL) by the end of 2018 [5]. In New York City (NYC), 77\% of PWH were virally suppressed in 2018, though stratified viral suppression rates indicate persistent disparities across multiple subgroups, including age, sex, gender, race, and transmission risk [6,7].

In 2009, the New York City Department of Health and Mental Hygiene (NYC Health Department) implemented a multi-component HIV Care Coordination Program (CCP) with the goal of improving engagement in care and treatment among the most vulnerable $\mathrm{PWH}$ in $\mathrm{NYC}$, including those facing the additional challenges of mental health issues, food insecurity, and unstable housing [8,9]. The program has since been included in the CDC's Compendium of Evidence-Based Interventions and Best Practices for HIV Prevention [10-12]. The initial CCP was implemented at 28 Ryan White Part A-funded agencies, reaching over 7,000 clients in less than four years. The CCP demonstrated modest benefits for viral load suppression among newly diagnosed PWH and previously diagnosed but consistently unsuppressed PWH $[9,13,14]$.

47 Refinements to the CCP to enhance intervention delivery and impact were implemented in 2018, and the program will likely continue to evolve.

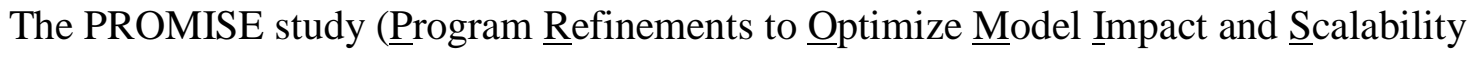
Based on Evidence) was launched in 2018 to assess and document the implementation of changes to the CCP. Based on the recognition that successful program implementation depends upon both client and provider engagement, we conducted a discrete choice experiment (DCE) to

53 understand provider preferences for specific program features. DCEs originated in econometrics

$54[15]$ and increasingly are being applied to questions in the public health and healthcare settings,

55 including HIV care and prevention [16-18]. Here we present the findings from the provider 56 DCE. 


\section{Methods}

59 Population and sampling

60 Ryan White Part A funding in NYC is used to fund services other than medical care, therefore our target population was comprised of non-medical providers in the core CCP positions of patient navigators/health educators, care coordinators/case managers, and program directors or other administrators at any of the 25 agencies implementing the revised CCP. All staff in those core program roles were eligible to participate. Ten agencies were community health centers, 6 were private hospitals, 3 were public hospitals, and 6 were community-based organizations. Eleven agencies were located in Brooklyn, 10 were located in Manhattan, 9 were located in the Bronx, 4 were located in Queens, and 1 was located in Staten Island. The study protocols and materials were reviewed and approved by the NYC Health Department institutional review board (IRB), which served as the IRB of record for the PROMISE study. All participants provided informed consent.

\section{Developing the attributes and levels}

We wanted to include aspects of the CCP that could be explored in both the current provider DCE and a subsequent client DCE in order to facilitate future concordance analyses. Following from this, and in accordance with best practices for designing DCEs [19,20], we began developing a list of program features to investigate in the DCE through two client focus groups (7 participants total) and one provider focus group (5 participants) See Table, Supplemental Digital Content 1 for participant details. Both providers and clients described and expressed positivity about CCP service features, particularly those supporting non-medical issues. Providers stressed matching CCP features to each client's particular needs.

We also considered which of the key elements of the program might be amenable to future changes, whether in program focus, intensity, or mode of delivery. The possible features and versions of those features, called attributes and attribute levels in the parlance of DCEs, were originally defined by reviewing focus group feedback and through discussion within the study team, and then refined based on feedback from PROMISE Study Advisory Board members at a meeting in June 2019. Our final design included four attributes with three to four levels each, which varied by focus, intensity, and/or mode: 1) help with adherence to ART; 2) help with primary care appointments; 3) help with issues other than primary care; and 4) where program 
medRxiv preprint doi: https://doi.org/10.1101/2021.10.21.21265350; this version posted October 25, 2021. The copyright holder for this preprint (which was not certified by peer review) is the author/funder, who has granted medRxiv a license to display the preprint in perpetuity.

It is made available under a CC-BY-NC-ND 4.0 International license .

visits happen (visit location). Black-and-white graphics (icons) were included to convey attribute levels and facilitate quick comprehension and comparison of the attribute levels across choice concepts. See Table 1 and Figure 1.

92

Table 1. Attributes and levels of a discrete choice experiment investigating provider preferences for HIV care coordination services in New York City

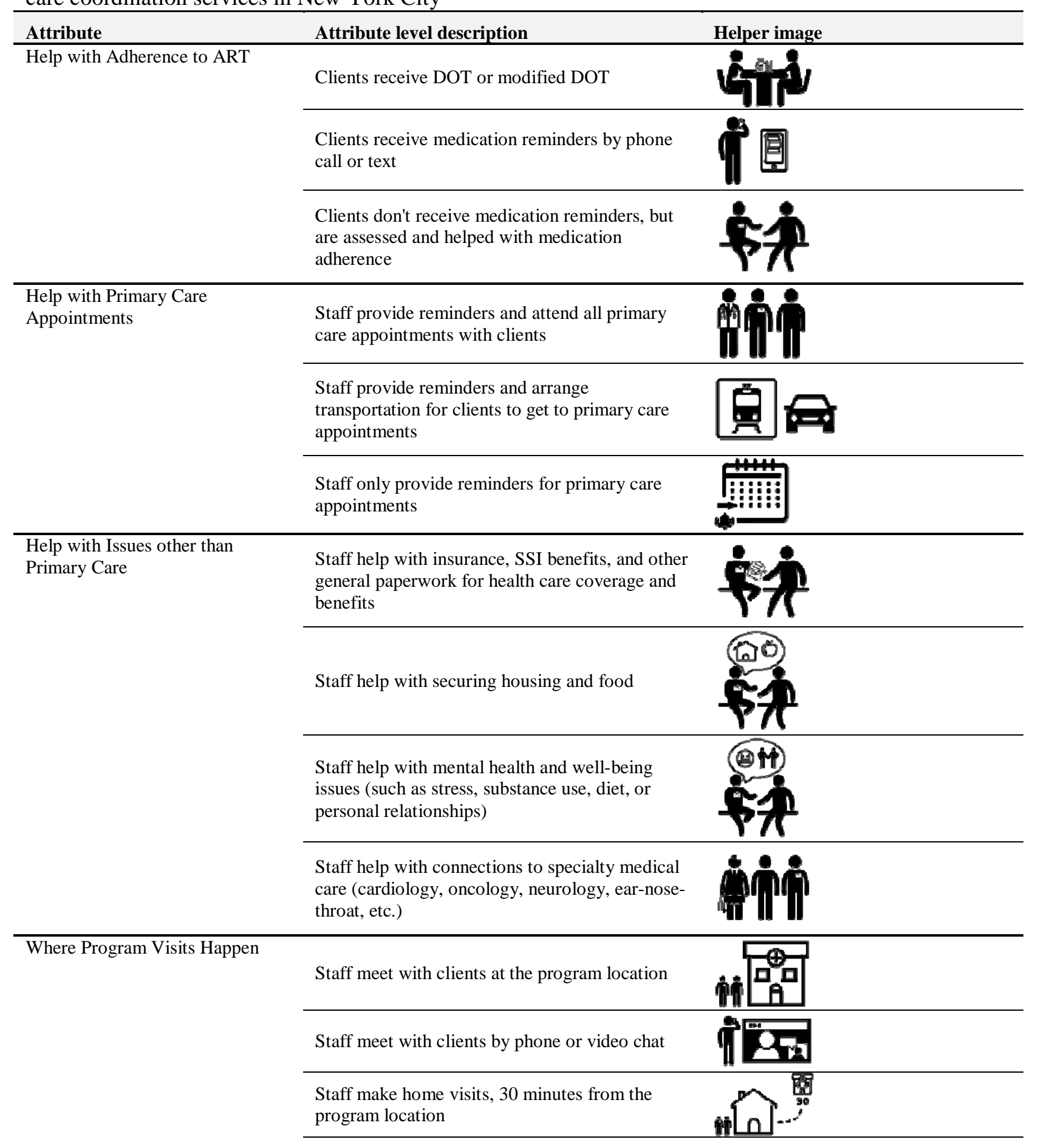




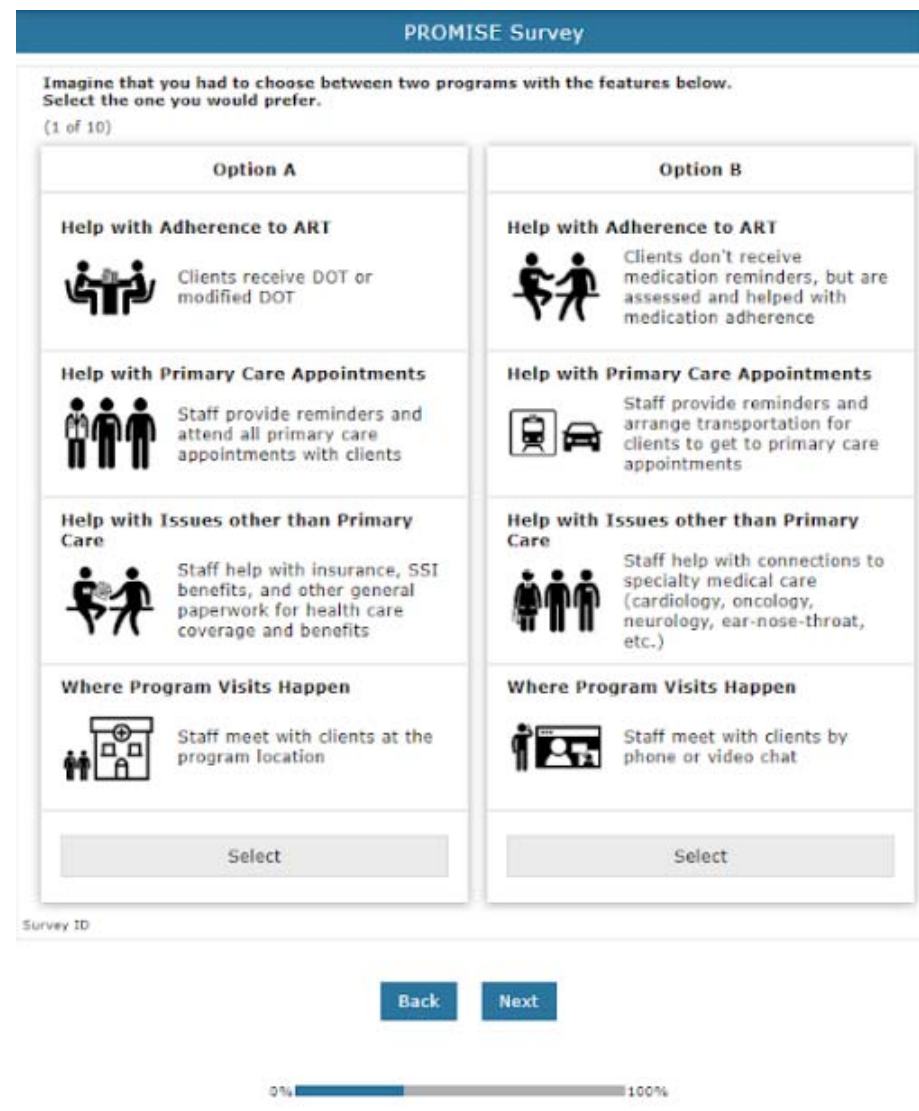

Figure 1. Example of discrete choice experiment (DCE) task presented to providers, desktop or laptop browser orientation.

DCE design

The survey was designed and implemented using Lighthouse Studio Version 9.8.1 (Sawtooth Software, Provo, Utah, USA) and deployed via Sawtooth's online survey hosting platform. The final design included ten comparison tasks, with two alternatives per choice task; to improve design efficiency and the precision of our main effects part-worth utility estimates, we chose not to include a "None" option. We used Sawtooth's Balanced Overlap method [21,22] to generate random tasks in which each level appeared approximately the same number of times as the other levels within each attribute (level balance), some level overlap within an attribute was permitted across alternatives in the same task, and levels within one attribute were included independently

107 of levels within other attributes (orthogonality). Our design's relative D-efficiency was $88 \%$ compared to the D-efficiency of Sawtooth's Completely Enumerated design, which is 
statistically more efficient but is less able to identify possible interaction effects due to minimal overlap between alternatives within a choice task [21]. The survey was deployed in English.

Introductory text was included to describe the attributes being investigated in the survey and explained that "Your responses will tell us what program features providers value most and what features they might like to change." In each choice exercise, we asked providers to "Imagine that you had to choose between two programs with the features below. Select the one that you would prefer." After the choice exercise we asked respondents about their age, race/ethnicity, and gender identity, and the length of time they had been providing CCP services.

\section{Sample size}

The minimum sample size for estimating main effects in a DCE can be calculated as $n \geq \frac{500 c}{t a}$, where $n$ is the number of respondents, $c$ is the maximum number of levels among all of the attributes, $t$ is the number of choice tasks, and $a$ is the number of alternatives per task [23,24]. This formula assumes each main-effect level appears at least 500 times within the survey design. The minimum sample size for our study given a maximum of 4 levels among our attributes, 10 choice tasks, and 2 alternatives per task is $\frac{500(4)}{(10)(2)}=100$, therefore, our target sample size of 150 responses was sufficient to estimate main effects.

\section{Data collection}

In January 2020, we emailed individual survey IDs and links to the online survey to 227 providers from the 25 revised CCP implementing agencies, with a target sample of 150 completed responses. The DCE could be completed in any modern browser on a desktop or laptop computer, tablet, or phone. Participants were compensated with $\$ 25$ gift cards upon completion of the survey. The survey was closed in early March 2020, before the first wave of the COVID-19 pandemic in NYC, with 152 respondents. Into the final survey data set we merged additional staff and agency descriptive data, such as staff role, agency location, and CCP budget, gathered from program liaisons and existing NYC Health Department contract records. 
We used Sawtooth Software's Lighthouse Studio 9.8.1 to design, administer, and analyze the survey. We estimated part-worth utilities for each attribute level using the hierarchical-Bayesian (HB) method and assuming the Random Utility Model, which posits that people choose the option that has the highest total utility for them [25]. The HB method analyzes the data at the individual level as well as the aggregate level, which yields more stable respondent-level estimates and also allows for more heterogeneity across respondents than other methods, such as traditional multinomial logistic regression [26,27].

\section{Part-worth utilities and relative importance}

147 We interpreted part-worth utilities as preferences for or endorsements of particular features. We

148 estimated part-worth utilities using effects coding, and zero-centered the estimates at the individual level in order to reduce the effect of noise on respondents' utility ranges $[15,28,29]$. We calculated relative importance at the respondent level as the range in part-worth utilities for levels within an attribute over the sum of the ranges in part-worth utilities for levels in all attributes; this yielded an importance score scaled from 0 to 1 for each respondent for each attribute. We then averaged this respondent-level measure to get an aggregate-level measure of attribute relative importance. Attribute relative importance is a way to quantify the degree to which an attribute influences choices across respondents relative to the other attributes.

\section{Model fit and respondent data quality}

158 We measured overall model fit using percent certainty, analogous to McFadden's pseudo- $\mathrm{R}^{2}$, 159 where values from 0.2 to 0.4 indicate a good model fit [30]. We also used the model's overall root likelihood (RLH) to evaluate model fit. RLH is the geometric mean of the likelihood of each

161 alternative within a choice task being selected, and ranges from $1 / n$ (worst fit) to 1 (best fit), 162 where $n$ is the number of alternatives per task [31,32]. In this study, an RLH of 0.5 would 163 indicate no model fit. We also assessed straightlining, response speed, and individual RLH 164 values, three common indicators of respondent quality in DCEs [33]. 


\section{Results}

167 Respondent Demographics and Agency Characteristics

168 Characteristics of the 152 respondents are described in Table 2. At least one provider responded 169 from each of the $25 \mathrm{CCP}$ provider agencies (median 6 respondents, IQR 4-7 respondents).

170 Median time to completion following consent was 7 minutes (IQR 5 minutes-12 minutes).

171 Providers who responded to the survey were primarily Black (34\%) or Latino/a (49\%),

172 identifying as women (68\%), and between 30 and 49 years old (60\%). Most respondents were

173 patient navigators (65\%) and had worked in Care Coordination for over two years (58\%). The

174 agencies at which most respondents worked were based in Manhattan (34\%), the Bronx (28\%),

175 or Brooklyn (24\%), were clinic-based (84\%) (vs community-based), and had experience with the 176 initial and revised Care Coordination model (76\%).

Table 2. Demographic and agency-level characteristics of providers $(\mathrm{N}=152)$

\begin{tabular}{lcc}
\hline $\begin{array}{l}\text { Demographic characteristics } \\
\text { Race/Ethnicity }\end{array}$ & Frequency & $\%$ \\
Asian & 6 & $4 \%$ \\
Black & 51 & $34 \%$ \\
Latino/Latina & 74 & $49 \%$ \\
White & 12 & $8 \%$ \\
Multi-racial & 2 & $1 \%$ \\
Other & 4 & $3 \%$ \\
Missing & 3 & $2 \%$ \\
& & \\
Age group & & \\
$20-29$ & 20 & $13 \%$ \\
$30-39$ & 59 & $39 \%$ \\
$40-49$ & 32 & $21 \%$ \\
$50-59$ & 29 & $8 \%$ \\
$60+$ & 12 & \\
& & $19 \%$ \\
Gender Identity & & $1 \%$ \\
Woman & 104 & $1 \%$ \\
Man & 43 & \\
Trans woman & 2 & $1 \%$ \\
Trans man & 1 & \\
Non-conforming & 1 & \\
Other & 1 &
\end{tabular}

\section{Role}


Care Coordinator-type staff

Administrative staff

Patient navigator-type staff

$\begin{array}{ll}33 & 22 \% \\ 20 & 13 \% \\ 99 & 65 \%\end{array}$

Length of time respondent has worked in Care Coordination

$<6$ months

$96 \%$

6 - 12 months

$21 \quad 14 \%$

1 - 2 years

$34 \quad 22 \%$

$>2$ years

\begin{tabular}{lcr}
\hline $\begin{array}{l}\text { Agency-level characteristics } \\
\text { Borough }\end{array}$ & Frequency & $\%$ \\
Bronx & & $28 \%$ \\
Brooklyn & 42 & $24 \%$ \\
Manhattan & 37 & $34 \%$ \\
Queens & 52 & $9 \%$ \\
Staten Island & 14 & $5 \%$
\end{tabular}

\section{Location}

Clinic-based

$128 \quad 84 \%$

Non-clinic

$24 \quad 16 \%$

\section{Care Coordination program experience}

Experienced with the initial and revised program

$116 \quad 76 \%$

New to Care Coordination under the revised program

$36 \quad 24 \%$

\begin{tabular}{lcc}
$\begin{array}{l}\text { Care Coordination budget calendar year } \\
\text { 2019 (median, IQR) }\end{array}$ & $\$ 758,333$ & $\$ 610,328-\$ 867,840$ \\
$<\$ 600,000$ & 24 & $16 \%$ \\
$\$ 600,000-\$ 750,000$ & 51 & $34 \%$ \\
$>\$ 750,000$ & 77 & $51 \%$ \\
\hline
\end{tabular}

\section{Relative importance}

181 Relative importance estimates for each attribute are shown in Table 3 and Figure 2. The attribute

182 that had the highest relative importance was visit location (28.6\%, 95\% CI $27.0 \%$ to $30.3 \%)$,

183 followed by how staff help with ART adherence (24.3\%, 95\% CI 22.4\% to 26.1\%), how staff

184 help with issues other than primary care (24.2\%, 95\% CI\% $22.7 \%$ to $25.7 \%)$, and lastly how staff 185 help with primary care appointments (22.9\%, 95\% CI $21.7 \%$ to $24.1 \%)$. 
medRxiv preprint doi: https://doi.org/10.1101/2021.10.21.21265350; this version posted October 25, 2021. The copyright holder for this preprint (which was not certified by peer review) is the author/funder, who has granted medRxiv a license to display the preprint in perpetuity.

It is made available under a CC-BY-NC-ND 4.0 International license .

Table 3. Average relative attribute importance from a discrete choice experience among providers in New York City assessing preference for HIV care coordination program features

\begin{tabular}{lrrrr}
\hline Attribute & Importance & Std Dev & $\begin{array}{r}\text { Lower } \\
\mathbf{9 5 \%} \text { CI }\end{array}$ & $\begin{array}{r}\text { Upper } \\
\mathbf{9 5 \%} \text { CI }\end{array}$ \\
\hline How staff help with ART adherence & $24.3 \%$ & $11.7 \%$ & $22.4 \%$ & $26.1 \%$ \\
How staff help with primary care appointments & $22.9 \%$ & $7.8 \%$ & $21.7 \%$ & $24.1 \%$ \\
How staff help with issues other than primary care & $24.2 \%$ & $9.6 \%$ & $22.7 \%$ & $25.7 \%$ \\
Visit location & $28.6 \%$ & $10.3 \%$ & $27.0 \%$ & $30.3 \%$ \\
\hline
\end{tabular}

Figure 2. Average relative attribute importance from a discrete choice experience among providers in New York City assessing preference for HIV care coordination program features

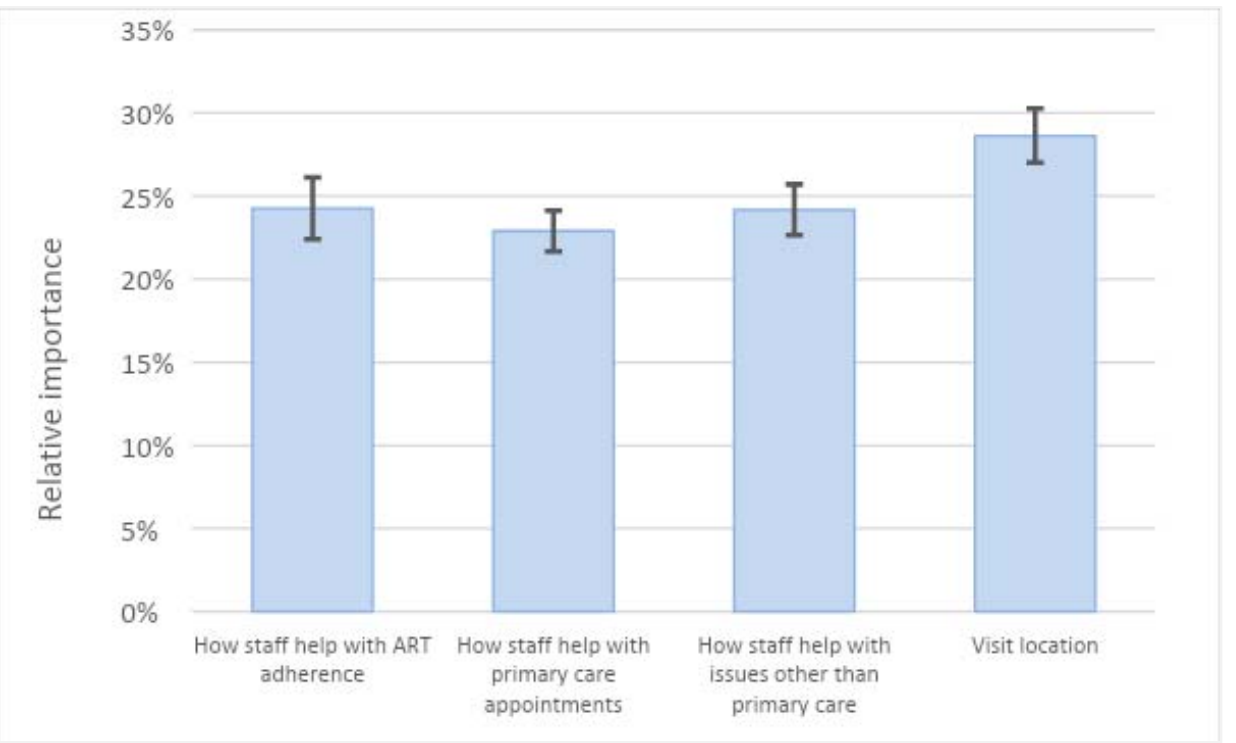

\section{Part-worth utilities}

Part-worth utilities of levels within each attribute are shown in Table 4 and Figure 3. The magnitude and direction of part-worth utilities indicate the strength of preference or endorsement for levels within an attribute. Providers preferred programs that included directly observed therapy as a strategy to help with ART adherence (part-worth utility 26.1, 95\% CI 19.1 to 33.1), compared to reminding clients to take ART via phone or text (-5.0,95\% CI -10.2 to 0.3) and only assessing and helping with ART adherence based on responses to assessments $(-21.1,95 \%$ CI -28.5 to -13.8). Providers preferred programs that offered reminders about and accompaniment to primary care appointments (20.8, 95\% CI 15.6 to 26.0) and those that reminded about and arranged transportation for primary care appointments $(17.4,95 \% \mathrm{CI} 12.7$ to $22.2)$, over those that only offered reminders about primary care appointments $(-38.2,95 \% \mathrm{CI}$ 43.3 to -33.0$)$. Providers preferred programs that focused on helping clients with connections to 

mental health and well-being (15.6, 95\% CI 11.2 to 20.0), compared with programs that focused on helping with insurance, Social Security, and other benefits paperwork $(2.1,95 \% \mathrm{CI}-2.6$ to 6.8) or helping with securing housing and food (-44.3, 95\% CI -48.9 to -39.6). Lastly, providers selected programs capable of providing home visits at locations up to 60 minutes away from the program or agency location (19.9, 95\% CI 10.7 to 29.0), and home visits up to 30 minutes away from the program or agency location $(8.2,95 \%$ CI 2.6 to 13.8$)$ more than programs in which staff only met clients at the program or agency $(1.6,95 \%$ CI -5.3 to 8.5$)$ or met clients only via phone or video chat $(-29.6,95 \%$ CI -35.8 to -24.1$)$.

Table 4. Part-worth utilities* from a discrete choice experience among providers in New York City assessing preference for HIV care coordination program features

\begin{tabular}{llrrrr}
\hline & & & & Lower & Upper \\
Attribute & Level & Utility & $\begin{array}{c}\text { Std } \\
\text { Dev }\end{array}$ & $\begin{array}{c}\text { 95\% } \\
\text { CI }\end{array}$ & $\begin{array}{c}\text { 95\% } \\
\text { CI }\end{array}$ \\
\hline How staff help & Directly observed therapy (DOT) & 26.1 & 44.1 & 19.1 & 33.1 \\
with ART & Reminder via phone or text & -5.0 & 33.1 & -10.2 & 0.3 \\
adherence & Adherence assessment & -21.2 & 46.1 & -28.5 & -13.8 \\
\hline How staff help & Remind \& accompany clients & 20.8 & 32.5 & 15.6 & 26.0 \\
with Primary care & Remind \& arrange transportation for clients & 17.4 & 29.9 & 12.7 & 22.2 \\
appointments & Remind only & -38.2 & 32.4 & -43.3 & -33.0 \\
\hline How staff help & Insurance, SSI benefits \& other paperwork & 2.1 & 29.3 & -2.6 & 6.8 \\
with issues other & Securing housing \& food & -44.3 & 29.3 & -48.9 & -39.6 \\
than primary care & Mental health \& well-being & 15.6 & 27.4 & 11.3 & 20.0 \\
& Connections to specialty medical care & 26.5 & 32.1 & 21.5 & 31.6 \\
\hline Visit location & At program/agency & 1.6 & 43.4 & -5.3 & 8.5 \\
& Via phone or video chat & -29.6 & 34.8 & -35.8 & -24.1 \\
& At clients' homes, 30 mins from program/agency & 8.2 & 35.3 & 2.6 & 13.8 \\
& At clients' homes, 60 mins from program/agency & 19.9 & 57.5 & 10.7 & 29.0 \\
\hline
\end{tabular}

*Note: Part-worth utilities were estimated using effects coding and are zero-centered 
Figure 3. Part-worth utilities* from a discrete choice experience among providers in New York City assessing preference for HIV care coordination program features

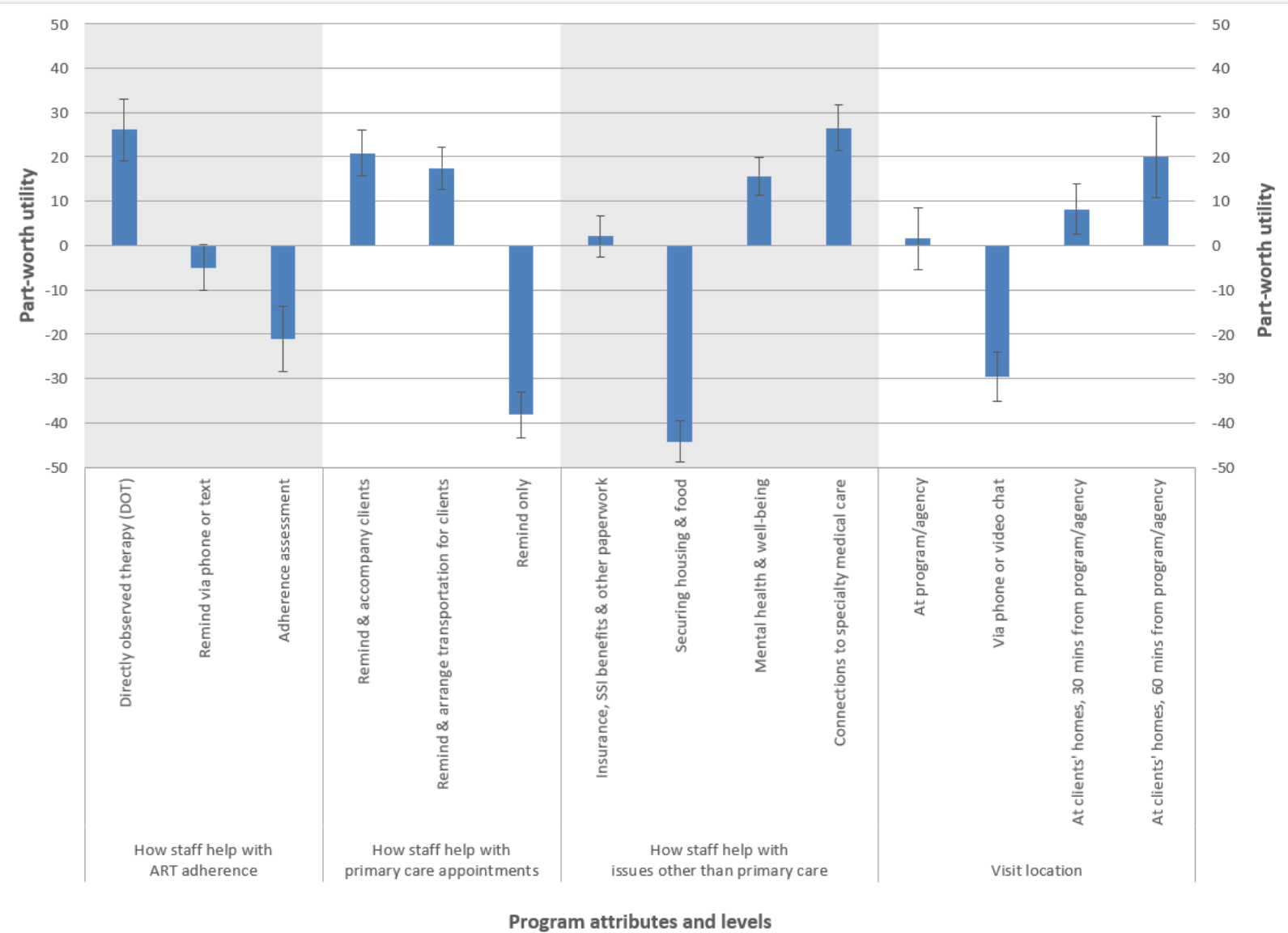

Program attributes and levels

Note: *Part-worth utilities were estimated using effects coding and are zero-centered

Model fit and respondent quality

219 Though we did not have any a priori hypotheses about interactions between attribute levels, all 220 possible interactions were explored, and none were found to be statistically significant. Overall

221 fit for our model measured using McFadden's pseudo $\mathrm{R}^{2}$ was 0.47 , and RLH for our model was

2220.69 , both indicating better model fit over the null model. We conducted additional analyses

223 excluding respondents identified through straightlining, fast response time, or low individual

224 RLH, and found that dropping potentially poor-quality respondents from the analysis made no

225 qualitative changes to part-worth utility or relative attribute importance estimates or our

226 interpretation of the results. 


\section{Discussion}

To our knowledge, provider preferences for features of HIV care coordination or HIV case management programs have not previously been systematically assessed. Among providers in New York City who took this survey about hypothetical variations on the HIV Care Coordination program, more intensive versions of services, such as DOT or accompanying clients to primary care appointments, were preferred over the less intensive alternatives, such as medication or appointment reminders alone.

The population for which the CCP is intended comprises $\mathrm{PWH}$ who have either documented risks for poor HIV outcomes, a clear history of poor HIV outcomes, or both. Our findings reflect an endorsement among participating providers of the high degree of support the program can potentially provide to these clients to help improve ART adherence. With regard to the preference for home visits, providers may have been affirming both the CCP model's value in filling service gaps in usual agency-based care as well as an aspect of the program that makes it effective for clients, who may live up to 60 minutes from the agency location if public transportation options are limited. This may be in recognition of the value of working with clients at their homes or in the field, regardless of the distance from the clinic.

Like home-based visits, DOT is time-intensive and costly, and is uncommon in other adherence-support programs. In the original CCP, clients were assigned to particular enrollment tracks, which determined the frequency and type of services they received. After the redesign in 2018, providers had more flexibility to adjust the frequency, type, and intensity of services based on periodic assessments of individual client needs. The redesign also included the option to provide DOT virtually. This expanded access to DOT for clients and reduced barriers to providing DOT for agencies. During the 2019 grant year (March 2019 - February 2020), 14.2\% of enrolled CCP clients received at least one DOT service, defined as the observation of a single dose, up from 7.7\% during the 2017 grant year (March 2017 - February 2018) [34].

Coordinating specialty medical care for non-HIV health conditions or engaging clients in mental health and well-being services are activities that providers are well-positioned to undertake in the $\mathrm{CCP}$, relative to other case management programs. However, our findings do not imply that providers devalue conventional case management activities. Because of how our DCE was designed, the levels within the 'Help with Issues other than Primary Care' attribute were mutually exclusive; in real life, a care coordination program could include support for 
medRxiv preprint doi: https://doi.org/10.1101/2021.10.21.21265350; this version posted October 25, 2021. The copyright holder for this preprint (which was not certified by peer review) is the author/funder, who has granted medRxiv a license to display the preprint in perpetuity.

It is made available under a CC-BY-NC-ND 4.0 International license .

housing and food and support for mental health and well-being. In fact, in recognition of the importance of supporting the whole client, the revised CCP includes reimbursable services related to helping with benefits and linking clients to housing and food services along with reimbursable services related to mental health and well-being. In this way, the CCP promotes the coordination of services across the social services and medical care systems to support the whole client. Similarly, this holistic approach to client care is reflected in the relative preferences for ways to provide more active assistance with primary care appointments.

\section{Limitations}

Our study has several limitations which should be acknowledged. Our sample may not be representative of all Care Coordination service providers in New York City Ryan White Part A agencies with regard to provider demographics or agency characteristics, which may limit the generalizability of our findings. We were unable to compare the frequencies of characteristics between respondents and non-respondents, because individual staff demographic data are not routinely collected by the NYC Health Department. Our sample may therefore not represent the full spectrum of preferences among all Care Coordination service providers, and may suffer from selection bias. However, all 25 Care Coordination-delivering agencies and all core Care Coordination staff roles were represented among the study participants.

Our study was limited by the constraints of DCE design, which must balance obtaining valuable and actionable data with limiting respondent cognitive fatigue. While including more or other attributes and levels would have yielded different findings, the attributes and levels in our study design capture the CCP features considered important by providers and clients of Care Coordination as ascertained through our focus groups.

Finally, our ability to interpret our findings is somewhat limited by the non-specific language framing our survey and the reliance on survey self-administration. We could not tell, for example, whether some providers may have made choices based on what they thought would make the program better for clients, while others may have been thinking more about what makes the program work for themselves or their agencies. However, our larger purpose was to understand what program attributes engage providers in service delivery and identify areas where provider engagement could be improved. Since either or both of these perspectives (benefit to clients or benefit to staff and agencies) could motivate providers to deliver the services they 
medRxiv preprint doi: https://doi.org/10.1101/2021.10.21.21265350; this version posted October 25, 2021. The copyright holder for this preprint (which was not certified by peer review) is the author/funder, who has granted medRxiv a license to display the preprint in perpetuity.

It is made available under a CC-BY-NC-ND 4.0 International license .

290

291

292

293

294

295

296

297

298

299

300

301

302

303

304

305

306

307

308

309

310

311

312

313

preferred in the DCE with high fidelity, and since the most preferred services were uniformly the more intensive options presented, we believe we may interpret our findings as indicating endorsement of and positive engagement with the unique and intensive features of the Care Coordination program.

\section{Conclusion}

Our goal in this part of the PROMISE study was to quantify providers' preferences for features of NYC HIV Care Coordination programs and to identify discordance between the stated preferences in the study and aspects of the CCP as designed. The CCP fills gaps in an often fragmented service system through comprehensive coordination of health care and psychosocial support services. We found consistent endorsement of the intensive client-focused features that are rare in case management-type programs, such as DOT and visiting clients in their homes. We believe our findings show that providers particularly value the availability of an array of flexible Care Coordination features that have the potential to make the greatest difference for the most vulnerable clients. In response to these findings, future revisions to the $\mathrm{CCP}$ could aim to enhance the sustainability of the delivery of the CCP's labor-intensive features.

\section{Competing Interests}

None declared.

\section{Authors' contributions}

$\mathrm{DN}$ and $\mathrm{MI}$ conceptualized the study. ABL conducted formative work. ABL, DN, MI, and RZ collaborated on the design of the data collection tool. RZ and CF performed statistical analyses. RZ, CF and MC wrote the first draft of the paper. RZ, CF, MC, ABL, MR, JC, GG, DN, and MI contributed to interpreting the data and to the writing and revising of the manuscript.

\section{Acknowledgements} Funding

Research reported in this publication was supported by the National Institute of Mental Health of the National Institutes of Health under Award Number R01MH117793. The content is solely the 
319 responsibility of the authors and does not necessarily represent the official views of the National

320 Institutes of Health.

322 We would like to acknowledge Sarah Kulkarni for her help with logistics and securing funding

323 for the study; Sarah Kozlowski for her help with logistics and recruitment; Kate Taylor for her

324 contribution to the conceptualization and drafting of the DCE; and Graham Harriman and the

325 PROMISE qualitative research team [Rachel Schenkel, Thamara Tapia, Miguel Hernandez and

326 Honoria Guarino], for their contributions to the larger project. We would also like to

327 acknowledge the PROMISE Study Advisory Board members for their contributions to the study

328 (in alphabetical order by last name): Mohammed Aldhuraibi for ACACIA Network, Lori Hurley

329 for the STAR Program at SUNY Downstate Medical Center, Tiffany Jules for Services for the

330 UnderServed, Inc., Genesis Luciano for AIDS Center of Queens County, Cyndi Morales for the

331 Council on Adoptable Children, and Vanessa Pizarro for COMPASS.

\section{Additional Files}

333 Additional file 1: Characteristics of focus group attendees

334 File format: docx. Table of characteristics of focus group attendees. 
medRxiv preprint doi: https://doi.org/10.1101/2021.10.21.21265350; this version posted October 25, 2021. The copyright holder for this preprint (which was not certified by peer review) is the author/funder, who has granted medRxiv a license to display the preprint in perpetuity.

It is made available under a CC-BY-NC-ND 4.0 International license .

\section{References}

1. Das M, Chu PL, Santos G-M, Scheer S, Vittinghoff E, McFarland W, et al. Decreases in Community Viral Load Are Accompanied by Reductions in New HIV Infections in San Francisco. PLOS ONE. 2010 Jun 10;5(6):e11068.

2. Cohen MS, Chen YQ, McCauley M, Gamble T, Hosseinipour MC, Kumarasamy N, et al. Prevention of HIV-1 infection with early antiretroviral therapy. N Engl J Med. 2011 Aug 11;365(6):493-505.

3. Lingappa JR, Hughes JP, Wang RS, Baeten JM, Celum C, Gray GE, et al. Estimating the Impact of Plasma HIV-1 RNA Reductions on Heterosexual HIV-1 Transmission Risk. PLOS ONE. 2010 Sep 13;5(9):e12598.

4. Montaner JSG, Lima VD, Barrios R, Yip B, Wood E, Kerr T, et al. Expanded HAART Coverage is Associated with Decreased Population-level HIV-1-RNA and Annual New HIV Diagnoses in British Columbia, Canada. Lancet. 2010 Aug 14;376(9740):532-9.

5. Centers for Disease Control and Prevention. Monitoring Selected National HIV Prevention and Care Objectives by Using HIV Surveillance Data-United States and 6 Dependent Areas, 2018. 25(2):104.

6. Ending the Epidemic Dashboard, NYC. People Newly Diagnosed with HIV, New York City (20062018) [Internet]. Ending the Epidemic. [cited 2020 Jul 19]. Available from: http://etedashboardny.org/data/new-diagnoses-and-linkage/new-diagnoses-trends-nyc/

7. Ending the Epidemic Dashboard, NYC. HIV Care Continuum - People Living with HIV. New York City (2018) [Internet]. Ending the Epidemic. [cited 2020 Jul 19]. Available from: http://etedashboardny.org/data/prevalence-and-care/hiv-care-cascades/nyc/

8. Irvine MK, Chamberlin SA, Robbins RS, Myers JE, Braunstein SL, Mitts BJ, et al. Improvements in HIV care engagement and viral load suppression following enrollment in a comprehensive HIV care coordination program. Clin Infect Dis. 2015 Jan 15;60(2):298-310.

9. Irvine MK, Chamberlin SA, Robbins RS, Kulkarni SG, Robertson MM, Nash D. Come as You Are: Improving Care Engagement and Viral Load Suppression Among HIV Care Coordination Clients with Lower Mental Health Functioning, Unstable Housing, and Hard Drug Use. AIDS Behav. 2017 Jun;21(6):1572-9.

10. Irvine M. HIV Care Coordination Program, Evidence-Informed for Retention in HIV Care [Internet]. 2020 [cited $2020 \mathrm{Jul}$ 19]. Available from: https://www.cdc.gov/hiv/pdf/research/interventionresearch/compendium//rc/cdc-hivintervention-Irc-ei-care-coordination-program.pdf

11. Irvine M. HIV Care Coordination Program (CCP) in Linkage to, Retention in, and Re-engagement in HIV care (LRC) Information Sheets [Internet]. Centers for Disease Control and Prevention Compendium of Evidence-Based Interventions and Best Practices for HIV Prevention. 2021. Available from: https://www.cdc.gov/hiv/pdf/research/interventionresearch/compendium//rc/cdc-hivHIV_Care_Coordination_Program_CCP_LRC_EBI_VS.pdf 
medRxiv preprint doi: https://doi.org/10.1101/2021.10.21.21265350; this version posted October 25, 2021. The copyright holder for this preprint (which was not certified by peer review) is the author/funder, who has granted medRxiv a license to display the preprint in perpetuity. It is made available under a CC-BY-NC-ND 4.0 International license .

12. Irvine M. HIV Care Coordination Program (CCP) in Structural Interventions (SI) Information Sheets [Internet]. Centers for Disease Control and Prevention Compendium of Evidence-Based Interventions and Best Practices for HIV Prevention. 2021. Available from: https://www.cdc.gov/hiv/pdf/research/interventionresearch/compendium/si/cdc-hivHIV_Care_Coordination_Program_CCP_SI_EBI.pdf

13. Nash D, Robertson MM, Penrose K, Chamberlin S, Robbins RS, Braunstein SL, et al. Short-term effectiveness of HIV care coordination among persons with recent HIV diagnosis or history of poor HIV outcomes. PLoS ONE. 2018;13(9):e0204017.

14. Robertson MM, Penrose K, Irvine MK, Robbins RS, Kulkarni S, Braunstein SL, et al. Impact of an HIV Care Coordination Program on Durable Viral Suppression. J Acquir Immune Defic Syndr. 2019 $01 ; 80(1): 46-55$.

15. Orme BK. Getting Started with Conjoint Analysis. Research Publishers, LLC; 2014. 234 p.

16. Zanolini A, Sikombe K, Sikazwe I, Eshun-Wilson I, Somwe P, Bolton Moore C, et al. Understanding preferences for HIV care and treatment in Zambia: Evidence from a discrete choice experiment among patients who have been lost to follow-up. PLoS Med. 2018;15(8):e1002636.

17. Dubov A, Ogunbajo A, Altice FL, Fraenkel L. Optimizing access to PrEP based on MSM preferences: results of a discrete choice experiment. AIDS Care. 2019;31(5):545-53.

18. Viney R, Lancsar E, Louviere J. Discrete choice experiments to measure consumer preferences for health and healthcare. Expert Rev Pharmacoecon Outcomes Res. 2002 Aug;2(4):319-26.

19. Bridges JFP, Hauber AB, Marshall D, Lloyd A, Prosser LA, Regier DA, et al. Conjoint Analysis Applications in Health-a Checklist: A Report of the ISPOR Good Research Practices for Conjoint Analysis Task Force. Value in Health. 2011 Jun;14(4):403-13.

20. Coast J, Horrocks S. Developing attributes and levels for discrete choice experiments using qualitative methods. J Health Serv Res Policy. 2007 Jan;12(1):25-30.

21. Sawtooth Software. Lighthouse Studio Help: CBC Questionnaires and Design Strategy [Internet]. 2020 [cited $2020 \mathrm{Jul} 28$ ]. Available from: https://legacy.sawtoothsoftware.com/help/lighthousestudio/manual/

22. Orme BK. Fine-Tuning CBC and Adaptive CBC Questionnaires (2009) [Internet]. [cited 2020 Jul 28]. Available from: https://sawtoothsoftware.com/resources/technical-papers/fine-tuning-cbc-andadaptive-cbc-questionnaires-2009

23. Orme BK. Sample Size Issues for Conjoint Analysis Studies (2019) [Internet]. [cited 2020 Jul 28]. Available from: https://sawtoothsoftware.com/resources/technical-papers/sample-size-issues-forconjoint-analysis-studies-2019

24. What Sample Sizes do you Need for Conjoint Analysis? [Internet]. Q Research Software. 2019 [cited $2020 \mathrm{Jul}$ 28]. Available from: https://www.qresearchsoftware.com/what-sample-sizes-doyou-need-for-conjoint-analysis 
medRxiv preprint doi: https://doi.org/10.1101/2021.10.21.21265350; this version posted October 25, 2021. The copyright holder for this preprint (which was not certified by peer review) is the author/funder, who has granted medRxiv a license to display the preprint in perpetuity.

It is made available under a CC-BY-NC-ND 4.0 International license .

25. Orme BK, Chrzan K. Becoming an Expert in Conjoint Analysis. Sawtooth Software, Inc; 2017. 327 p.

26. CBC/HB Technical Paper (2009) [Internet]. [cited 2020 Aug 6]. Available from: https://sawtoothsoftware.com/resources/technical-papers/cbc-hb-technical-paper-2009

27. Application of Covariates within Sawtooth Software's CBC/HB Program: Theory and Practical Example (2009) [Internet]. [cited 2020 Aug 6]. Available from: https://sawtoothsoftware.com/resources/technical-papers/application-of-covariates-withinsawtooth-softwares-cbc-hb-program-theory-and-practical-example-2009

28. Raw utilities vs. Zero-Centered Diffs - Sawtooth Software Forum [Internet]. [cited 2020 Sep 24]. Available from: https://legacy.sawtoothsoftware.com/forum/7160/raw-utilities-vs-zero-centereddiffs?show=7160\#q7160

29. Scaling Conjoint Part Worths: Points vs. Zero-Centered Diffs [Internet]. [cited 2020 Sep 25]. Available from: https://legacy.sawtoothsoftware.com/about-us/news-and-events/sawtoothsolutions/ss10-cb/1201-scaling-conjoint-part-worths-points-vs-zero-centered-diffs

30. Hauber AB, González JM, Groothuis-Oudshoorn CGM, Prior T, Marshall DA, Cunningham C, et al. Statistical Methods for the Analysis of Discrete Choice Experiments: A Report of the ISPOR Conjoint Analysis Good Research Practices Task Force. Value Health. 2016;19(4):300-15.

31. Hill AR. The CBC System for Choice-Based Conjoint Analysis [Internet]. Sawtooth Software Technical Paper Series. 2017 [cited 2020 Sep 23]. Available from: https://sawtoothsoftware.com/uploads/sawtoothsoftware/originals/CBC\%20Technical\%20Paper\% 20(2017).pdf

32. Comparing HB Root-likelihood (RLH) Between Displayr and Sawtooth [Internet]. Displayr. 2019 [cited 2020 Sep 23]. Available from: https://www.displayr.com/comparing-hb-rlh/

33. Identifying "Bad" Respondents [Internet]. [cited 2020 Oct 17]. Available from: https://sawtoothsoftware.com/help/lighthousestudio/manual/hid_web_maxdiff_badrespondents.html

34. New York City Department of Health and Mental Hygiene. Unpublished data. Care and Treatment Program, Bureau of HIV; 2021. 